\title{
The Macroeconomic Policy Effect on Nigerian Agricultural Performance: One-Step Dynamic Forecasting Analysis
}

\author{
Ernest Simeon Odior ${ }^{1}$ \\ ${ }^{1}$ Department of Economics, Faculty of Social Sciences, University of Lagos, Nigeria \\ Correspondence: Ernest Simeon Odior, Department of Economics, Faculty of Social Sciences, University of \\ Lagos, Akoka Lagos, Nigeria. Tel: 234-806-208-8200 or 234-705-807-4040. E-mail: odiorsimerny@yahoo.com \\ or eodior@unilag.edu.ng
}

Received: January 10, 2014

Accepted: June 19, 2014

Online Published: August 25, 2014

doi:10.5539/ijef.v6n9p190

URL: http://dx.doi.org/10.5539/ijef.v6n9p190

\begin{abstract}
This study attempted to examines the consequences of macroeconomic policy indicators on agricultural performance in Nigeria. The data set for this study consists of annual time series from 1970-2012. The study employ a one-step dynamic forecast model to analysis the nature of this impact. To ensure stationarity of the data, the study uses the individual root of Im, Pesaran and Shin unit root test. The result showed that real monetary aggregate, technological change introduced overtime and pass level of agricultural sector performance play a crucial role in affecting the agricultural gross domestic product in Nigeria. It is found that credit to agricultural sector and government expenditure on agriculture has less significant impact on agricultural performance. These findings support the growing view that revealed that the changes of macroeconomic policy instruments had substantial effect on the agricultural sector. It was recommended that policies should be designed to ensure high performance in the agricultural sector attract little or no interest and future favourable policies on agricultural development should be streamlined and implemented coherently.
\end{abstract}

Keywords: macroeconomic policy, agricultural performance, dynamic forecasting

\section{Introduction}

Macroeconomics is the "big picture" of an economy's overall performance. The policies that governments use are of particular importance in influencing the economy as a whole. Macroeconomic tools consist of fiscal policiesthe level of government spending and the balance between taxation and spending-and monetary policies-the control of the availability of money and access to credit. In the United States for example, the changes of macroeconomic indicators are highly affected through interest rates and inflation

Researchers and economists believed that macroeconomic policy changes often have substantial impacts on agricultural economy worldwide. Although policymakers try to design policies to improve the national economy, these policies often have unintended and harmful effects on the agricultural economy.

World farm economy has been more sensitive to the changes of macroeconomic circumstances this century. Falling global commodity prices, slower domestic demand, and base-effect of increasing world fuel prices in 2008 have become more challenged for government in stimulating the economy without endangering macroeconomic stability. Moreover, the international financial crisis which began in 1997 continues affecting agricultural sector, mainly on external trade (Ali et al., 2010).

Agricultural sector performance in Nigeria was shrinking due to macroeconomic policy distortions and South African agriculture was decelerated, mainly due to macroeconomic indicators, particularly changes in both exchange rates and interest rates (Ukoha, 1999). Notwithstanding policies have been trying to formulate, they often have unintended and unpredictable effects on agricultural sector, and major players usually have little considerations in structuring and forming the policies. Additionally, developing countries are predicted to face a slowdown in agricultural growth resulting from the price intervention through trade, exchange rates, and other macroeconomic indicators (Schiff \& Valdes, 1998).

The agricultural sector in Nigeria is one of the leading sectors in the country in terms of its contributions to income, employment, foreign exchange earnings and domestic food supply. Nigeria with its several ecological zones and climatic conditions supports the cultivation of a wide variety of food and tree crops (Omojimite, 2012). Also, 
one of the major drivers of overall growth in Nigeria, therefore, remained the agricultural sector, which contributing 30.3, 31.0 and 33.1 per cent in 2010, 2011 and 2012, respectively, to the nominal GDP (CBN, 2012). Also, sectoral analysis of quarterly real GDP showed that the agricultural output declined as its relative contribution to the growth in real GDP decreased from 1.70 per cent in the third quarter of 2012 to 1.43 per cent in the fourth quarter of 2012. The decline in activities in this sector was attributable to the decrease in the relative contribution of crop production, livestock and forestry from $1.47,0.13$ and 0.03 per cent in the preceding quarter to $1.21,0.12$ and 0.02 per cent in the current quarter, respectively. The contribution of forestry remained the same at 0.03 per cent (see CBN, 2012). Further analysis of the agricultural sector shows that the improved performance in crop production sub-sector relative to the preceding quarter was mainly driven by all the major crops.

To boost agricultural output in Nigeria in 2013, a total of N2,923.6 million was guaranteed to 16,349 farmers under the Agricultural Credit Guarantee Scheme (ACGS) in the third quarter of 2013. This represented an increase of 213.5 above the level in the preceding quarter, but indicated a decline of 27.5 per cent below the level in the corresponding quarter of 2012. A sub-sectoral analysis of the loans guaranteed indicated that the food crops sub-sector received the largest share of N1,708.7 million (58.4 per cent) for 10,969 beneficiaries, while the livestock sub-sector got N458.9 million (15.7 per cent) for 3,192 beneficiaries. Fisheries sub-sector obtained N130.3 million (4.5 per cent) for 410 beneficiaries; while cash crop sub-sector received N47.8 million (1.6 per cent) guaranteed to 120 beneficiaries. Mixed crops obtained N540.4 million (18.5 per cent) guaranteed to 1,438 beneficiaries, while 'Others' sub-sector obtained N37.5 million (1.3 per cent) guaranteed to 220 beneficiaries. At end-September 2013, the total amount released by the CBN under the Commercial Agriculture Credit Scheme (CACS) to the participating banks for disbursement stood at N221.9 billion for 294 (two hundred and ninety four) projects (CBN, 2013).

But the sectoral contributions to the growth in nominal non-oil GDP in 2013 indicated that all the sectors decreased in the current quarter. Agriculture decreased from 5.49 per cent recorded in the preceding quarter to 3.10 per cent in the review period. In the Agricultural and Services sectors, all the sub-sectors recorded decreases in their relative contributions to nominal GDP (CBN, 2013).

For a developing country like Nigeria that has embraced macroeconomic adjustment and deregulation, it is believed that, the macroeconomic environment strongly influences the overall viability of agricultural performance and the effects of agricultural policy. Therefore, the need for this study cannot be overemphasized. The paper discusses briefly key aspects of the macroeconomic policy that shape the pace and pattern of agricultural performance in the Nigeria and there is a prior set of research questions that this study seeks to address, this includes: (1) what are the impacts of such macroeconomic policies on agricultural performance? (2) Do monetary policy (monetary shocks) at the national level has an influence on agricultural performance? (3) And does fiscal irresponsibility affect agricultural performance? It was noted that these kind of questions have gained urgency in recent discussions both of agricultural and macro policies. In evaluating the impact of macroeconomic policy changes, the mix of monetary and fiscal policies has to be evaluated.

Hence, the broad objective of this paper is to identify, within an empirical framework, the proportionality relationship and dynamic interactions between macroeconomic policy and agricultural performance with a view to enhancing accurately forecast the agricultural output in Nigeria between 1970 and 2012, which is explained by variations in control variables given in this study. Thus, the structure of the paper is as follows. After the introduction part, section 2 provides a brief review of the literature on macroeconomic policy and agricultural performance while, section 3 establish some of the macroeconomic policies affecting agriculture. Estimation strategy and model specification are describe in section 4. Section 5 discusses the empirical results in the study and section 6 and 7 is the policy implication and recommendation and conclusions.

\section{Brief Review of Relevant Literature}

There are large numbers of theoretical and empirical studies, which have recorded the relationships of macroeconomic variables and agricultural sector. The studies of Han, Jansen and Penson (1990), Robertson and Orden (1990) are evidential of the impact of monetary policy on the agricultural sector. Similarly, the studies of Groenewegen (1986), Orden (1986), Saghaian et al. (2002), were focused on exchange rates, which were considered as a mean of influence from the macroeconomic policy to the agricultural sector while, the studies of Zanias (1994, 1999), Loizou et al. (1997) and Tabakis (2001) were focused on the relationship between the general level of prices and the level of agricultural prices.

An article by Schuh (1974) has been the starting point, which initiated the interest on the effects of macroeconomic policy for agriculture. This article focused on foreign exchange rates, which were considered to 
be as a mean of macroeconomic policy transmission to agriculture. The adoption of euro as a common currency in ÛË will do away with foreign exchange rates fluctuations in intra-community trade. Nevertheless, in trading with third countries the role of foreign exchange rates remains unchanged.

Having thought this issue becomes more essential, numerous studies have been conducted to examine the influences of macroeconomic variables on agricultural sector (Baek \& Koo, 2007, 2009). The findings include changes in interest rates and inflation could affect cost of production, agricultural land prices, agricultural input prices, and commodity prices. In the Philippines, the macroeconomic environments strongly influenced the overall viability of agriculture (Intal, 1985).

In the earlier paper (Alagh, 2011c) macroeconomic linkages with agriculture were focused on. Alternative ways of looking at Indian agriculture were differentiated. The question that emerged is: Is there a structural constraint in Indian agriculture or does Indian agriculture work in a system in which as demand rises and prices rise, on account of macro-economic reasons, supply responds. The constraints could be institutional or policy determined in the food grains part of the economy, with the non-food grain economy being responsive to market and non-price factors mattering particularly in that part of agriculture not responding to prices.

\section{Macro-Economic Policies Affecting Agriculture}

The specific goal of macroeconomic policy is to help the nation pursue general goals of full employment, low or zero inflation, and growth in national income and economic output. Macroeconomic policy has three dimensions namely: monetary policy, fiscal policy and trade policy. Since all of these policies are closely related and interdependent, macroeconomic policy is often described as a "policy mix" of monetary, fiscal, and trade policies. Determining the appropriate policy mix is the responsibility of the main actors in macroeconomic policy: the central banks and the Congress, and the President (Snell et al., 1997). The federal government tries to influence the performance of the national economy through various macroeconomic policies such as changing the level of taxation, government spending, or the supply of money available in the economy.

Agricultural producers and consumers are heavily influenced by macro-economic polices even though they often have little influence over the setting of these nation-wide policies. Three categories of macro-economic policies affect agriculture: monetary and fiscal policies, foreign exchange rate policies, factor price (interest, wage and land rental rates), natural resource, and land use policies. Changes in monetary, fiscal and trade policies affect the performance of the agricultural economy through their respective influences on input and output prices, land prices, and exchange rates. The agricultural economy is very sensitive to changes in interest rates and inflation and thus monetary policy changes.

Monetary and fiscal policies are the core of macro-economic policy because together they influence the rate of price inflation in the national economy, as measured by increases in indexes of consumer or producer prices. Monetary policies refer to controls over the rate of increase in the country's supply of money and hence the aggregate demand in the economy. If the supply of money is increased faster than the growth of aggregate goods and services, inflationary pressure ensues. Fiscal policies refer to the balance between the government taxing policies that raise government revenue and the public expenditure policies that use that revenue. When government spending exceeds revenue, the government runs a fiscal deficit. That result creates inflation if the deficit is covered by expanding the money supply.

Foreign exchange rate policies directly affect agricultural prices and costs. The foreign exchange rate is the conversion ratio at which domestic currency exchanges for foreign currency. Most agricultural commodities are traded internationally, and most countries either import or export a portion of their agricultural demand or supply. For internationally tradable commodities, the world price sets the domestic price in the absence of trade restrictions (as explained in the session on price determination). The exchange rate thus directly influences the price of an agricultural commodity because the domestic price (in local currency) of a tradable commodity is equal to the world price (in foreign currency) times the exchange rate (the ratio of domestic to foreign currency) (Pearson, 2002).

A depreciation of the exchange rate means that not only does the price of imports increase in terms of domestic currency, but also import substituting commodities become more competitive. For example, devaluation would raise the price of imported cereals and increase demand for domestically produced cereals. The price of domestically produced cereals rises up to point where it equals the import price and production increases replacing imports. Similarly, exchange rate depreciation causes the domestic price of exported commodities to fall in terms of foreign exchange and to raise in terms of domestic currency thus stimulating production

Factor price policies directly affect agricultural costs of production. The primary factors of production are land, 
labour, and capital. Land and labour costs typically make up a substantial portion of the costs of producing most agricultural commodities in developing countries. Governments often enact macro policies that affect land rental rates, wage rates, or interest rates throughout the economy. Other factor price policies, such as minimum wage floors or interest rate ceilings, influence some sectors more than others. Some governments introduce special policies to attempt to control land uses or to govern the exploitation of natural resources, such as minerals or water. These macro policies can also influence the costs of agricultural production.

Another equally important factor of influence of macroeconomic policy in agriculture is the increasing instability in agricultural product prices, as a result of macroeconomic instability. The existence of a non-neutral relationship between the general level of prices and the level of agricultural prices could be explained through a series of models, Fischer (1981), Zanias (1999), in which the case of the unexpected inflation holds a significant place.

\section{Estimation Strategy and Methodology}

The estimation technique consists of three steps procedure. First, the unit root test, using the individual root of Im, Pesaran and Shin unit root test. Second, the least squares estimation of the model with an autoregressive and AR(1) series. Autoregressive was included to enables account for serial correlation and create short run dynamic forecasts of one-step forecasts and finally, analysis of forecast evaluation. Third, evaluate the dynamic forecasts of the model goodness of fit.

The dynamic forecasts are true one-step forecasts (from the start of the forecast sample), since they use the recursively computed forecast of the lagged value of the dependent variable. Both the lagged dependent variable and the lagged residuals forecasted dynamically. These forecasts may be interpreted as the forecasts for subsequent periods that would be computed using information available at the start of the forecast sample.

The variables under consideration include; the agricultural gross domestic product, (the dependent variable) is used as a proxy for agricultural performance (AGP). The macroeconomic variables (the independent variables) include: real monetary aggregate (RMA), exchange rates (EXRt), inflation rate (INF), nominal interest rate on Loan (NIR), credit to agricultural sector (CAS), government expenditure on agriculture (GEA), and time trend (TIM) representing technological change have been introduced overtime. The data set for this paper consists of annual time series from 1970-2012; they were obtained from the Central Bank of Nigeria Statistical Bulletins (CBN, 2011, 2012)

\subsection{The Model: Dynamic Forecasting}

In the general form we can augment the earlier specification of the model to include the first lag of $y$ :

$$
\text { y c x z y(-1) }
$$

With dynamic forecasting, we perform a multi-step forecast of $y$, beginning at the start of the forecast sample.

For our single lag specification above in equation (1) we have the one-step ahead forecast,

$$
\hat{y}_{S}=\hat{c}_{0}+\hat{c}_{1} x_{S}+\hat{c}_{2} z_{S}+\hat{c}_{3} y_{S-1}
$$

where $y_{S-1}$ is the value of the lagged endogenous variable in the period prior to the start of the forecast sample.

The initial observation in the forecast sample (equation 2) will use the actual value of lagged Y. Thus, $S$ if is the first observation in the forecast sample,

Forecasts for subsequent observations will use the previously forecasted values of Y:

$$
\hat{y}_{S+k}=\hat{c}_{0}+\hat{c}_{1} x_{S+k}+\hat{c}_{2} z_{S+k}+\hat{c}_{3} y_{S+k-1}
$$

If there are additional lags of $y$ in the estimating equation, the above algorithm is modified to account for the non-availability of lagged forecasted values in the additional period. For example, if there are three lags of $y$ in the equation:

i. The first observation $(S)$ uses the actual values for all three lags, $y_{S-3}, y_{S-2}$ and $y_{S-1}$.

ii. The second observation $(S+1)$ uses actual values for $y_{S-2}$ and $y_{S-1}$ the forecasted value $y_{S-1}$ of the first lag of $y_{S+1}$.

iii. The third observation $(S+2)$ will use the actual values for $y_{S-1}$ and forecasted values $\hat{y}_{S+1}$ and $\hat{y}_{S}$ for the first and second lags of $y_{S+2}$.

iv. All subsequent observations will use the forecasted values for all three lags. 
The forecasting model took the actual acreage and output numbers in each year and predicted the next years. Therefore the stochastic equation in its empirical forms is specified as follow:

$$
\begin{aligned}
& \log A G P_{t}=\alpha_{0}+\sum_{j=1}^{n} \alpha_{1} \log R M A_{t}+\sum_{j=1}^{n} \alpha_{2} E X R_{t}+\sum_{j=1}^{n} \alpha_{3} I N F_{t}+\sum_{j=1}^{n} \alpha_{4} N I R+\sum_{j=1}^{n} \alpha_{5} \log C A S_{t}+\sum_{j=1}^{n} \alpha_{6} \log G E A \\
& +\sum_{j=1}^{n} \alpha_{7} T I M++\sum_{j=1}^{n} \alpha_{8} \log A G P(-1)_{t}+A R(1)+U_{1 t}
\end{aligned}
$$

Equation (4) is designed to examine the short run dynamic relationship that exists between the dependent variable, the agricultural performance (AGP) in period $t$ and the independent variables, the macroeconomic variables include: real monetary aggregate $\left(\mathrm{RMA}_{\mathrm{t}}\right)$, exchange rates $\left(\mathrm{EXR}_{\mathrm{t}}\right)$, Inflation Rate $\left(\mathrm{INF}_{\mathrm{t}}\right)$, Nominal Interest Rate on Loan $\left(\mathrm{NIR}_{t}\right)$, Credit to Agricultural Sector $\left(\mathrm{CAS}_{t}\right)$, Government Expenditure on Agriculture $\left(\mathrm{GEA}_{t}\right)$, and Time trend representing technological change have been introduced overtime $\left(\mathrm{TIM}_{\mathrm{t}}\right)$. The model above (equation 4$)$ could have been used to give smooth forecasts for a number of years, but that was not the motivation since this was not a model of long term growth. It was intended to predict the consequences of macro policies on agricultural output. This is to see how those explanatory variables influence the growth rate of agricultural performance in the short run (1970-2012).

The a-priori assumptions for the above model (equation 4) are: $\alpha_{0}>0, \alpha_{1}>0 \alpha_{2}<0, \alpha_{3}<0, \alpha_{4}<0 \alpha_{5}>0 \alpha_{6}>0, \alpha_{7}>$ $0 \alpha_{8}>0$. The implication of $\alpha, s>0$ is that a positive relationship exist between the dependent variable and independent variables. This implies that an increase in these independent variables will lead to an increase in the agricultural performance, while, $\alpha, s<0$ imply that there is a negative relationship between the dependent variable and the independent variables. This means that an increase in the independent variables will lead to a decrease in the agricultural performance. The expectations of the model are quite clear from the apriori signs of the coefficients based on economic literatures.

\section{Empirical Results}

\begin{tabular}{|c|c|c|c|c|c|c|c|}
\hline \multicolumn{8}{|l|}{ Sample: 19702012} \\
\hline \multicolumn{8}{|c|}{ Series: LOGAGP, LOGRMA, EXR, INF, NIR, LOGCAS, LOGGEA, TIM } \\
\hline \multirow{2}{*}{\multicolumn{4}{|c|}{ Method: Im, Pesaran and Shin W-stat }} & \multirow{2}{*}{\multicolumn{3}{|c|}{$\begin{array}{c}\text { Statistic } \\
-13.3376 \\
\end{array}$}} & Prob.** \\
\hline & & & & & & & 0.0000 \\
\hline \multicolumn{8}{|c|}{ ** Probabilities Are Computed Assuming Asymptotic Normality } \\
\hline \multicolumn{8}{|c|}{ Intermediate ADF test results } \\
\hline Series & t-Stat & Prob. & $\mathrm{E}(\mathrm{t})$ & $\mathrm{E}($ Var $)$ & Lag & Max Lag & Obs \\
\hline D(LOGAGP) & -4.5641 & 0.0038 & -2.173 & 0.655 & $\mathrm{I}(1)$ & 1 & 41 \\
\hline D(LOGRMA) & $-3.6321 *$ & 0.0392 & -2.173 & 0.653 & $\mathrm{I}(1)$ & 1 & 41 \\
\hline $\mathrm{D}(\mathrm{EXR})$ & -6.2117 & 0.0000 & -2.173 & 0.653 & $\mathrm{I}(1)$ & 1 & 41 \\
\hline $\mathrm{D}(\mathrm{INF})$ & -6.4639 & 0.0000 & -2.177 & 0.687 & $\mathrm{I}(1)$ & 1 & 40 \\
\hline $\mathrm{D}(\mathrm{NIR})$ & -7.3124 & 0.0000 & -2.177 & 0.687 & $\mathrm{I}(1)$ & 1 & 40 \\
\hline D(LOGCAS) & -6.9354 & 0.0000 & -2.173 & 0.653 & $\mathrm{I}(1)$ & 1 & 41 \\
\hline D(LOGGEA) & -9.0061 & 0.0000 & -2.173 & 0.653 & $\mathrm{I}(1)$ & 1 & 41 \\
\hline Average & -6.0689 & & -2.175 & 0.651 & & & \\
\hline \multicolumn{8}{|c|}{ Dropped from Test } \\
\hline Average & -6.2812 & & -2.174 & & \multicolumn{2}{|c|}{0.664} & \\
\hline \multirow[t]{3}{*}{ Test critical values: } & \multicolumn{2}{|c|}{$1 \%$ level } & & & \multicolumn{2}{|c|}{-4.211868} & \\
\hline & \multicolumn{2}{|c|}{$5 \%$ level } & & & -3.529 & & \\
\hline & \multicolumn{2}{|c|}{$10 \%$ level } & & & -3.196 & & \\
\hline
\end{tabular}

Table 1. Summary of results of unit root tests (im, pesaran and shin)

Source: Author's Computation.

Note. (*) significant at $5 \%$ and $10 \%$ critical Values.

To ensure stationarity of the data we employed the group unit root test of the individual root, of the Im, Pesaran and Shin unit root test, because data often exhibit trending behaviour or stationarity in the mean. These tests were applied to determine whether the trending data should be first differenced or regressed on deterministic functions of time to render the data stationarity, also, to determine the number of co integration relationships. 
Also, the unit root test is necessary because research has shown that non-stationary data leads to spurious regression, which may affect in determining the cointegration relation in the long run. The summary of the results of the tests are presented in Table 1 below.

The results in Table 1 show that, LOGAGP, LOGRMA, EXR, INF, NIR, LOGCAS, LOGGEA, were integrated at order one, that is I(1). In other words, they were stationary at first difference. Comparing the variables first difference values (the ADF unit root test statistic) with the critical values and various probabilities, the Im, Pesaran and Shin unit root test statistics show that the variables are integrated at order of one I(1), looking at the group absolute ADF test statistic of 13.3376 and the average 6.2812. Time variable was dropped from the unit root test series because of it deterministic trend behaviour.

Furthermore, this implies that all the series are non-stationary at levels except. Therefore the null hypothesis $(\rho=$ $1)$ is accepted at levels and the null hypothesis $(\rho=1)$ that the series are non-stationary after the first difference is rejected for all the series. For the random walk above, this implies that there is an existence of unit root, so it is an I(1) series. We therefore concluded that the series are of order one I(1). These are MacKinnon critical values for the rejection of hypothesis of a unit root. Next we look for the short run dynamic linear relationship using the least squares result.

Table 2. Summary of estimated results

\begin{tabular}{|c|c|c|c|c|c|}
\hline \multicolumn{6}{|c|}{ Dependent Variable: LOGAGP } \\
\hline \multicolumn{6}{|c|}{ Sample (adjusted): 19712012} \\
\hline Variable & Coefficient & & Std. Error & t-Statistic & Prob. \\
\hline $\mathrm{C}$ & $\alpha_{0}$ & 3.033660 & 1.741111 & 1.742370 & 0.0914 \\
\hline LOGRMA & $\alpha_{1}$ & 0.239935 & 0.231350 & 1.037105 & 0.3080 \\
\hline EXR & $\alpha_{2}$ & -0.001583 & 0.001328 & -1.192141 & 0.2429 \\
\hline INF & $\alpha_{3}$ & -0.002632 & 0.001768 & -1.488475 & 0.1474 \\
\hline NIR & $\alpha_{4}$ & -0.010922 & 0.006168 & -1.770715 & 0.0868 \\
\hline LOGCAS & $\alpha_{5}$ & 0.051019 & 0.103473 & 0.493066 & 0.6257 \\
\hline LOGGEA & $\alpha_{6}$ & 0.054237 & 0.036811 & 1.473385 & 0.1511 \\
\hline TIM & $\alpha_{7}$ & 0.213886 & 0.069196 & 3.091039 & 0.0043 \\
\hline LOGAGP(1) & $\alpha_{8}$ & 0.237146 & 0.170018 & 1.394830 & 0.1730 \\
\hline $\mathrm{AR}(1)$ & & 0.376760 & 0.214172 & 1.759144 & 0.0884 \\
\hline R-squared & \multicolumn{2}{|l|}{0.897836} & \multicolumn{2}{|c|}{ Mean dependent var } & 11.97765 \\
\hline Adjusted R-squared & \multicolumn{2}{|l|}{0.897164} & \multicolumn{2}{|c|}{ S.D. dependent var } & 2.674494 \\
\hline Durbin-Watson stat & \multicolumn{2}{|l|}{2.088810} & \multicolumn{2}{|c|}{ Prob(F-statistic) } & 0.000000 \\
\hline Inverted AR Roots & \multicolumn{2}{|l|}{0.84} & & & \\
\hline
\end{tabular}

Source: Author's Computation.

A look at the regression result in Table 2 above indicates partial conformity of the result with the postulated theory that LOGAGP is positively related to RMA, CAS, GEA, TIM and its passed value AGP(-1) and negatively related to EXR, INF and NIR. The coefficients of determinations are partially in line with our apriori expectations. Furthermore, an examination of the results shows a good fit in terms of the standard error of the parameters $\left(\operatorname{Std} \alpha_{0}>\operatorname{Std} \alpha_{1}-\operatorname{Std} \alpha_{8}\right)$ (1.741). The result show non-negative constant term for agricultural performance (3.034).

From the estimated result in Table 2, it is obvious that exchange rates $\left(\mathrm{EXR}_{\mathrm{t}}\right)$, inflation rate $\left(\mathrm{INF}_{\mathrm{t}}\right)$, nominal interest rate. It also cleared that real monetary aggregate $\left(\mathrm{RMA}_{\mathrm{t}}\right)$, credit to agricultural sector $\left(\mathrm{CAS}_{\mathrm{t}}\right)$, government expenditure on agriculture $\left(\mathrm{GEA}_{\mathrm{t}}\right)$, and Time trend representing technological change have been introduced overtime $\left(\mathrm{TIM}_{\mathrm{t}}\right)$ and its passed value of agricultural performance $\mathrm{AGP}(-1)$ are positively related to current agricultural performance.

The low probabilities values of TIME, strongly rejected null hypotheses and indicate that this variable is significant, that is technological change being introduced overtime is much significant in determining agricultural performance in Nigeria. The high probability of values real monetary aggregate $\left(\mathrm{RMA}_{\mathrm{t}}\right)$, credit to agricultural sector $\left(\mathrm{CAS}_{\mathrm{t}}\right)$, government expenditure on agriculture $\left(\mathrm{GEA}_{\mathrm{t}}\right)$ and its passed value of agricultural performance AGP(-1) strongly accepted the null hypotheses and indicated that the variables are less significant in explaining agricultural performance in Nigeria undermining their positive impact. The result also shows that nominal interest 
rate on loan $\left(\mathrm{NIR}_{\mathrm{t}}\right)$ has strong negative impact on agricultural output. For this paper we are performing the test at the $10 \%$ significance level, that is, a p-value that ranges between $0.01-0.10$ are taken as evidence to reject the null hypothesis of a zero coefficient.

From the on-going discussion, it is obvious that technological change being introduced overtime will be the most important variable in significance is much felt. The autoregressive result show that only $90 \%$ of variations in the agricultural performance are accounted for by the changes in the explanatory variables, while, the Durbin-Watson (DW) test statistic $\left(\mathrm{d}^{*}\right)$ shows the presence of no serial correlation between the error terms.

\section{Agricultural Performance Trend (1970-2012)}

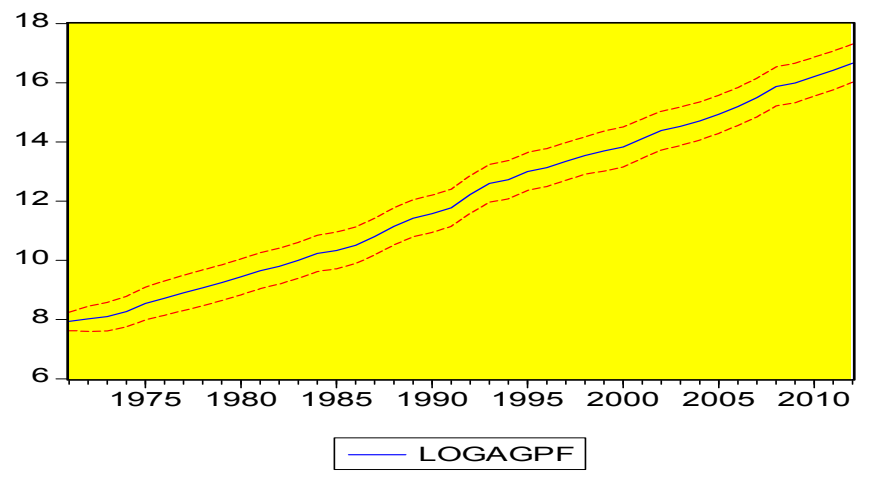

\begin{tabular}{|ll|}
\hline \multicolumn{2}{|l|}{ Forecast: LOGAGPF } \\
Actual: LOGAGP \\
Forecast sample: 19702012 \\
Adjusted sample: 19712012 \\
Included observations: 42 \\
Root Mean Squared Error & \\
Mean Absolute Error & 0.267434 \\
Mean Abs. Percent Error & 0.215824 \\
Theil Inequality Coefficient & 1.713805 \\
Bias Proportion & 0.010806 \\
Variance Proportion & 0.023479 \\
Covariance Proportion & 0.171767 \\
\hline
\end{tabular}

Figure 1. Dynamic forecast evaluation: the goodness of fit

Our dynamic forecasts are one-step forecasts (from the start of the forecast sample), the results used the recursively computed forecast of the lagged value of the dependent variable. Fig 1, comparing the root mean squared error and mean absolute error statistics, which depend on the scale of the dependent variable, showed that the errors will get smaller in the long run. This implies that the forecasting ability of that models in the short run are good but the long run model will seem better forecasted.

Also, observation from Fig 1 above show scale invariants. The Theil inequality coefficient lies between zero and one, it is close to zero, and this indicates a perfect fit. The bias proportion shows that the mean of the forecast is not different from the mean of the actual series being close to zero, while the variance proportion of the variation of the forecast is also not different from the variation of the actual series. The covariance proportion which measures the remaining unsystematic forecasting errors shows that only 0.80 unsystematic forecasting errors were not measures.

Finally, note that the bias, variance, and covariance proportions add up to one. If the forecast is "good", the bias and variance proportions should be small so that most of the bias should be concentrated on the covariance proportions. This is showed in the Figure 1; it implies our models are good fit.

\section{Policy Implication and Recommendations}

Several macroeconomic policies have been used in Nigeria, which have directly and indirectly influenced agricultural output growth. Thus, macroeconomic indicators have been considered to be important factors affecting farm economy in Nigeria. This paper assesses the macroeconomic policies adopted in Nigeria and the effect of these policies on agricultural output growth overtime.

The results show that the country's exchange rate regime has not encouraged agricultural export lately. For example, a weakened Nigerian Naira (or Naira depreciation) tends to increase Nigerian agricultural exports through a decrease in Nigerian agricultural prices and enhancing Nigerian farm income, as well. Although credit to the sector had no significant effect on agricultural output growth, its availability greatly depends on how high the nominal interest rates are. Similarly, lower interest rates in Nigeria facilitate a higher farm income and lower production costs without necessarily compensating with a decrease in prices of outputs. Hence, it is important to examine macro-agricultural sector linkages to better understand both the causes and the consequences of changes in Nigerian farm income.

Following the result of the analysis, some policy measures were recommended to achieve increase agricultural production and capacity utilization rate in Nigeria. The macroeconomic policy environment most conducive to 
agricultural growth and productivity requires flexibility in interest rates and exchange rates combined with a less expansionary financial policy. On the whole, macroeconomic policies that reduce inflation, increase foreign private investment in agriculture, introduce favourable exchange rates, make agricultural credit to have significant effect on agricultural output growth would be invaluable in fortifying government expenditure in the sector and ensure agricultural output growth in Nigeria.

Also, farmers, agribusinesses, and policymakers must understand the policy process and be aware of the impact that changing macroeconomic policies can have on agricultural markets. This knowledge will put them in a better position to react strategically to actual or anticipated changes in the macro economy or to influence farm leaders and policymakers to design macroeconomic policies that benefit agriculture.

The study also reveals that periodic increase in the tariff rate of agricultural product import in the short and long run is an incentive to increase technology based capacity utilization in agricultural sector in Nigeria. Hence a policy measure that should ensures periodic upward review of agricultural product tariff is strongly advocated.

\section{Conclusion}

The main purpose of this study is to assess the short run dynamic impact between some macroeconomic indicators and agricultural performance in Nigeria and to discuss these key indicators of macroeconomics that influence agricultural growth patterns. In the estimation technique, the study uses the Im, Pesaran and Shin unit root test to determine the series stationarity and create short run dynamic forecasts of one-step in the analysis of the forecast evaluation.

The results have shown the existence of significant, less significant and insignificant relationships between variables of the macroeconomic policy and the agricultural performance in Nigeria. The result showed that technological change introduced overtime play a crucial role (positive) in affecting the farm income in Nigeria. These results further stress the fact that macroeconomic policy decisions (real monetary aggregate, credit to agricultural sector, government expenditure on agriculture, exchange rate, inflation rate, nominal interest rate and the passed value of agricultural performance are strongly reflected on the agricultural sector and thus they perform a very important role in any effort towards price stability in this sector. Though some are less significant (real monetary aggregate, credit to agricultural sector, government expenditure on agriculture), while other (the nominal interest rate) having negative impact.

Finally, finding from the results of this study suggest the importance of the Nigerian government to intensify price policy measures that will enhance increased agricultural output and the result of this study would provide useful guidelines, particularly for the government and policy makers in developing policy framework effectively and planning future strategies for agricultural development. Subsequently, future policies on agricultural development would be streamlined and implemented coherently

\section{References}

Alagh, M. (2011c). Agricultural Economy of India and Macro-Economic Effects: Some Empirical Results and a Research Agenda based on the Literature. W.P. No. 2011-09-01, IIM Ahmedabad.

Benson, U. O. (2012). Institutions, Macroeconomic Policy and the Growth of the Agricultural Sector in Nigeria. Global Journal of Human Social Science, 12(1).

Central Bank of Nigeria. (2011). Statistical Bulletin. December.

Central Bank of Nigeria. (2012). Economic Report.

Central Bank of Nigeria. (2012). Quarter Four. Quarterly Statistical Bulletin, 1(4).

Central Bank of Nigeria. (2013). Statistics Department. Quarterly Statistical Bulletin, 2(3).

Fischer, S. (1981). Relative Shocks, Relative Price Variability, and Inflation. Brooking Papers on Economy Activity, 2, 381-431. http://dx.doi.org/10.2307/2534344

Groenewegen, J. (1986). Exchange Rates and the Canadian Grain Sector. Working Paper, 1/86 Agricultural Canada.

Han, D. B., Jansen, D. W., \& Penson, J. B. (1990). Variance of Agricultural Prices, Industrial Prices, and Money. American Journal of Agricultural Economics, 72, 1066-1073. http://dx.doi.org/10.2307/1242638

Intal, P. S. (1985). The Macroeconomic Policy Environment of Philippine Agricultural Performance. Journal of Philippine Development, 22(2).

Jungho, B., \& Won, W. K. (2009). Analysing Factors Affecting U.S. Food Price Inflation'Paper presented at the 
International Agricultural Trade Research Consortium. Analytic Symposium Confronting Food Price Inflation: Implications for Agricultural Trade and Policies. Seattle, Washington.

Loizou, E., Mattas, K., \& Pagoulatos, A. (1997). Macro-Monetary Effects on Agricultural Prices: The Case of Greek Agriculture. Applied Economic Letters, 4, 397-401. http://dx.doi.org/10.1080/135048597355113

Orden, D. (1986). A Critique of Exchange Rate Treatment in Agricultural Trade Models' Comment. American Journal of Agricultural Economics, 68, 990-993. http://dx.doi.org/10.2307/1242146

Orden, D. (1986). Money and Agriculture, the Dynamics of Financial Market Agricultural Trade Linkages. Agricultural Economics Research, 14-28.

Robertson, J. C., \& Orden, D. (1990). Monetary Impacts on Prices in the Short and Long Run' some evidence from New Zealand. American Journal of Agricultural Economics, 72, 160-171. http://dx.doi.org/10.2307/1243156

Roslina, A., Abu Kasim, A., Engku, E. E. A., \& Fazleen, A. F. (2010). Determining the Linkages of Macroeconomics Indicators and Agricultural Variables in Nigeria. Prosiding Perkem, 2, 455-459.

Saghaian, S., Reed, M., \& Marchant, M. (2002). Monetary Impacts and Over-Shooting of Agricultural Prices in an Open Economy. American Journal of Agricultural Economics, 84(1), 90-103. http://dx.doi.org/10.1111/1467-8276.00245

Schiff, M., \& Valdes, A. (1998). Agriculture and the Macroeconomy. Handbook of Agricultural Economics, World Bank.

Schuh, G. E. (1974). The Exchange Rate and U.S. Agriculture. American Journal of Agricultural Economics, 56, 1-13. http://dx.doi.org/10.2307/1239342

Scott, P. (2002). A Framework for Agricultural Policy Analysis Stanford University.

Tabakis, N. (2001). A Multivariate Model For The Relationship between Agricultural Prices and Inflation Uncertainty, Evidence Using Greek Data. Agricultural Economics Review, 2(1), 28-38.

Ukoha, O. O. (1999). Macroeconomics Policy and the Effects on Agricultural Output in Nigeria' Federal university of Agriculture. College of Agricultural Economics, Rural Sociology and Extension, Nigeria.

William, M., Snell, M., Marchant, A., \& Craig, L. I. (1997). Macroeconomic Policy Linkages to Agriculture. University of Kentucky Cooperative Extension Service.

Zanias, Ù. Đ. (1994). Inflation, Agricultural Prices and Economic Convergence in Greece. European Review of Agricultural Economics.

Zanias, Ù. Đ. (1999). Seasonality and Spatial Integration in Agricultural (Product) Markets. Agricultural Economics, 2, 253-262. http://dx.doi.org/10.1016/S0169-5150(99)00006-7

\section{Copyrights}

Copyright for this article is retained by the author(s), with first publication rights granted to the journal.

This is an open-access article distributed under the terms and conditions of the Creative Commons Attribution license (http://creativecommons.org/licenses/by/3.0/). 